Article

\title{
Optimizing the Dosing Regimens of Daptomycin Based on the Susceptible Dose-Dependent Breakpoint against Vancomycin-Resistant Enterococci Infection
}

\author{
Wichai Santimaleeworagun ${ }^{1,2}$, Dhitiwat Changpradub ${ }^{3}{ }^{\mathbb{D}}$, Sudaluck Thunyaharn ${ }^{4}$ and \\ Jatapat Hemapanpairoa $5, *$ (D) \\ 1 Department of Pharmacy, Faculty of Pharmacy, Silpakorn University, Nakorn Pathom 73000, Thailand; \\ swichai1234@gmail.com \\ 2 Pharmaceutical Initiative for Resistant Bacteria and Infectious Diseases Working Group (PIRBIG), \\ Nakorn Pathom 73000, Thailand \\ 3 Division of Infectious Disease, Department of Medicine, Phramongkutklao Hospital, Bangkok 10400, \\ Thailand; Dhitiwat@yahoo.com \\ 4 Faculty of Medical Technology, Nakhonratchasima College, Nakhon Ratchasima 30000, Thailand; \\ tanmicro@gmail.com \\ 5 Department of Pharmacy Practice and Pharmaceutical Care, Faculty of Pharmaceutical Sciences, \\ Burapha University, Chonburi 20131, Thailand \\ * Correspondence: jatapathemapanpairoa@gmail.com; Tel.: +66-3839-040-1
}

Received: 14 November 2019; Accepted: 28 November 2019; Published: 29 November 2019

\begin{abstract}
Daptomycin, a lipopeptide antibiotic, is one of the therapeutic options used for the treatment of vancomycin-resistant enterococci (VRE). Recently, the Clinical and Laboratory Standards Institute (CLSI) M100 30th edition has removed the susceptibility (S) breakpoint for Enterococcus faecium and replaced it with a susceptible dose-dependent (SDD) breakpoint of $\leq 4 \mu \mathrm{g} / \mathrm{mL}$, with a suggested dosage of $8-12 \mathrm{mg} / \mathrm{kg} /$ day. Herein, we aimed to determine the minimum inhibitory concentration (MIC) values of daptomycin against clinical VRE isolates and to study the appropriate daptomycin dosing regimens among critically ill patients based on the new susceptibility CLSI breakpoint. The MIC determination of daptomycin was performed using E-test strips among clinical VRE strains isolated from patients at the Phramongkutklao Hospital. We used Monte Carlo simulation to calculate the probability of target attainment (PTA) and the cumulative fraction of response (CFR) of the ratio of the free area under the curve to $\mathrm{MIC}\left(f \mathrm{AUC}_{0-24} / \mathrm{MIC}\right)>27.4$ and $f \mathrm{AUC}_{0-24} / \mathrm{MIC}>20$ for survival and microbiological response, respectively, at the first day and steady state. Further, we determined that the simulated daptomycin dosing regimen met the minimum concentration ( $\mathrm{Cmin}$ ) requirements for safety of being below $24.3 \mathrm{mg} / \mathrm{L}$. All of the $48 \mathrm{VRE}$ isolates were E. faecium strains, and the percentiles at the 50th and 90th MIC of daptomycin were 1 and $1.5 \mu \mathrm{g} / \mathrm{mL}$, respectively. At MIC $\leq 2 \mu \mathrm{g} / \mathrm{mL}$, a daptomycin dosage of $12 \mathrm{mg} / \mathrm{kg} /$ day achieved the PTA target of survival and microbiological response at the first $24 \mathrm{~h}$ time point and steady state. For a MIC of $4 \mu \mathrm{g} / \mathrm{mL}$, none of the dosage regimens achieved the PTA target. For CFR, a dosage of $8-12 \mathrm{mg} / \mathrm{kg} /$ day could achieve the $90 \%$ CFR target at the first day and steady state. All dosing regimens had a low probability of $\mathrm{Cmin}$ being greater than $24.3 \mathrm{mg} / \mathrm{L}$. In conclusion, the MIC of VRE against daptomycin is quite low, and loading and maintenance doses with $8 \mathrm{mg} / \mathrm{kg} /$ day were determined to be optimal and safe.
\end{abstract}

Keywords: daptomycin; Enterococcus faecium; MIC; Monte Carlo simulation; VRE 


\section{Introduction}

The prevalence of vancomycin-resistant enterococci (VRE), a nosocomial pathogen, is increasing, especially for Enterococcus faecium. Invasive VRE infections are commonly found among intensive care unit (ICU) patients and are associated with high mortality and long-term hospitalization [1-3]. Daptomycin and linezolid are first-line antibiotics for treating VRE infections [4-7]. Daptomycin, a lipopeptide antibiotic, plays an important role in the treatment of serious infections or infections in immunocompromised patients requiring bactericidal antibiotics [8,9].

Currently, daptomycin is approved for treatment of complicated skin and soft tissue infections as well as Staphylococcus aureus bacteremia with right-side endocarditis. Daptomycin is clinically used for VRE treatment; however, a standard dose (4-6 mg/ $/ \mathrm{kg} /$ day) of daptomycin for VRE bloodstream infection has been shown to result in a poorer survival rate than a high dose of $\geq 9 \mathrm{mg} / \mathrm{kg} /$ day [10-12]. Moreover, the Clinical and Laboratory Standards Institute (CLSI) M100 30th edition has removed the susceptibility (S) breakpoint for E. faecium and replaced it with a minimum inhibitory concentration (MIC) susceptible dose-dependent (SDD) breakpoint of $\leq 4 \mu \mathrm{g} / \mathrm{mL}$. Regarding this new susceptibility breakpoint for enterococci, CLSI suggests a daptomycin dosing regimen of $8-12 \mathrm{mg} / \mathrm{kg} / \mathrm{day}$, while for other enterococci species, the susceptible MIC breakpoint at $2 \mu \mathrm{g} / \mathrm{mL}$ remains in place, with a recommended daptomycin dose of $6 \mathrm{mg} / \mathrm{kg} /$ day $[13,14]$.

Daptomycin has concentration-dependent bactericidal activity and its pharmacokinetic and pharmacodynamic (PK/PD) target for efficacy is the ratio of the area under the curve to MIC $\left(\mathrm{AUC}_{0-24} / \mathrm{MIC}\right)$ or the ratio of the free area under the curve to $\mathrm{MIC}\left(f \mathrm{AUC}_{0-24} / \mathrm{MIC}\right)[15,16]$. According to the SDD breakpoint with a high dose of daptomycin, VRE treatment has to achieve its PK/PD target to reduce the risk of underdosing daptomycin. In the same way, a high dose of daptomycin may increase the risk of creatine phosphokinase (CPK) elevation, and musculoskeletal toxicity is associated with doses at the minimum concentration (Cmin) [10,17]. In critically ill patients, an alteration in drug pharmacokinetics can occur [18-20], so optimal dosing of daptomycin is of great concern. The purpose of this study is to assess the in vitro activity of daptomycin as well as to evaluate dosing regimens of daptomycin in critically ill patients based on its PK/PD target for efficacy and safety against VRE isolates.

\section{Results}

\subsection{Pharmacodynamic Profiling}

All of the 48 studied VRE clinical isolates were E. faecium strains. The $\mathrm{MIC}_{50}$ and $\mathrm{MIC}_{90}$ for vancomycin were 128 and $>128 \mu \mathrm{g} / \mathrm{mL}$, respectively. Daptomycin MIC values against VRE isolates ranged from 0.38 to $4 \mu \mathrm{g} / \mathrm{mL}$. The $\mathrm{MIC}_{50}$ and $\mathrm{MIC}_{90}$ values were 1 and $1.5 \mu \mathrm{g} / \mathrm{mL}$, respectively. Daptomycin resistance among VRE isolates was not observed (Figure 1).

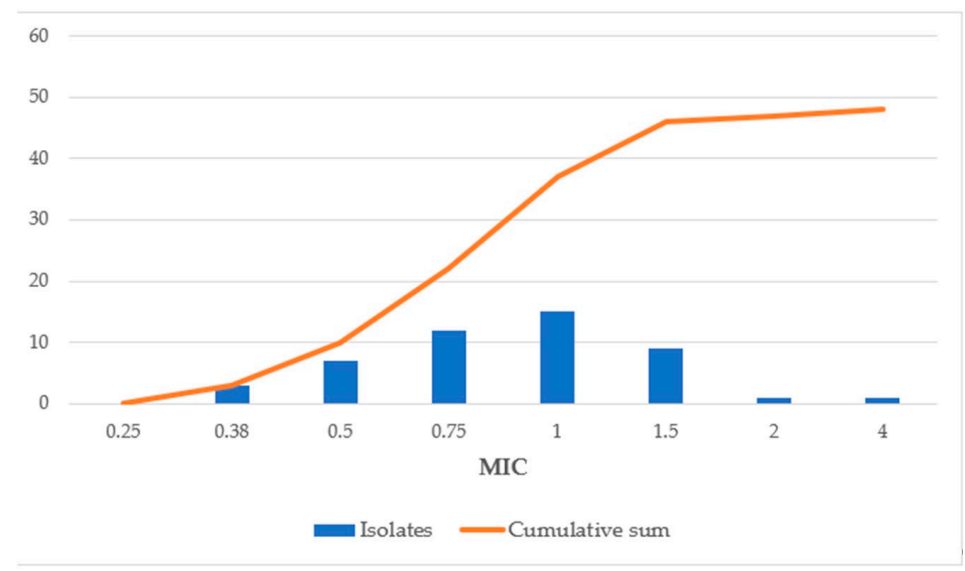

Figure 1. In vitro activities of daptomycin against 48 vancomycin-resistant enterococci (VRE) strains. Note: Nonduplicate susceptibility method. 


\subsection{Pharmacokinetic and Pharmacodynamic Analysis and Dosing Simulations}

The probability of target attainment (PTA) of daptomycin dosing regimens at specific MICs with target $\mathrm{fAUC}_{0-24} / \mathrm{MIC}>27.4$ and $\mathrm{fAUC}_{0-24} / \mathrm{MIC}>20$ during the first $24 \mathrm{~h}$ and at the steady state are shown in Figures 2 and 3, respectively. Target attainment for all regimens during the first $24 \mathrm{~h}$ was lower than steady state. None of the dosing regimens exceeded $90 \%$ for a MIC of $4 \mu \mathrm{g} / \mathrm{mL}$. The dosing regimen of $12 \mathrm{mg} / \mathrm{kg}$ every $24 \mathrm{~h}$ of daptomycin gave the target attainment of $\mathrm{fAUC}_{0-24} / \mathrm{MIC}>27.4$, which exceeded $90 \%$ for a MIC of $\leq 2 \mu \mathrm{g} / \mathrm{mL}$ during first $24 \mathrm{~h}$ and at steady state, respectively. For daptomycin at a MIC of $1 \mu \mathrm{g} / \mathrm{mL}$, dosing of $6 \mathrm{mg} / \mathrm{kg} /$ day exceeded the $90 \%$ PTA of fAUC ${ }_{0-24} / \mathrm{MIC}$ targets. All daptomycin dosing regimens gave a Cmin of daptomycin below $24.3 \mathrm{mg} / \mathrm{mL}$ (Table 1).

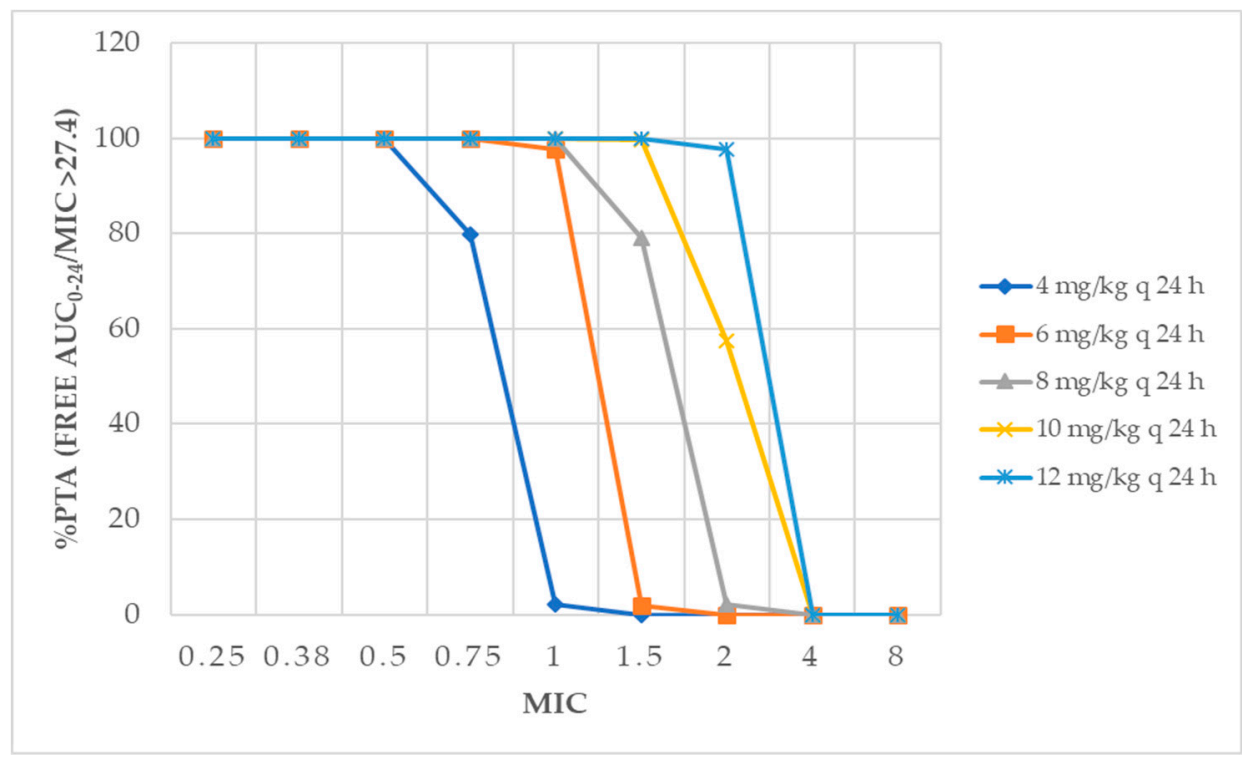

(a)

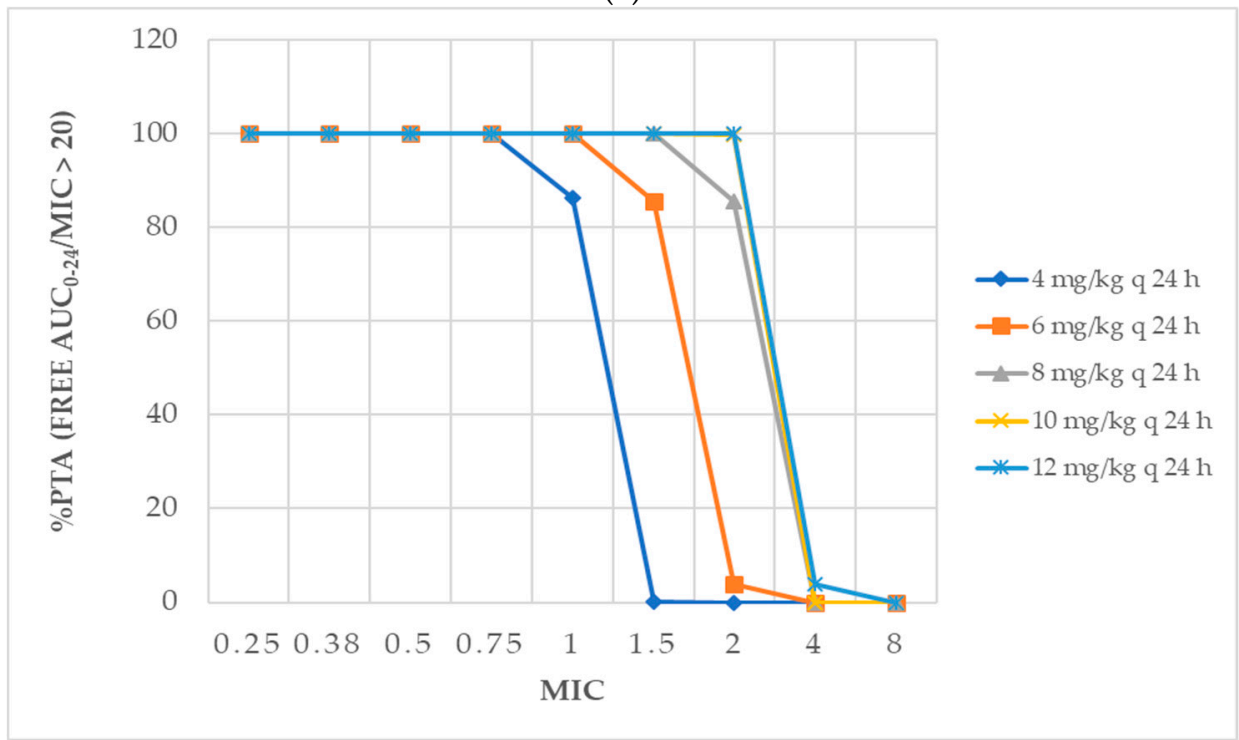

(b)

Figure 2. The percentage of probability of target attainment (PTA) for the different daptomycin dosings for critically ill patients during the first $24 \mathrm{~h}$ with targets of $f \mathrm{AUC}_{0-24} /$ minimum inhibitory concentration (MIC) $(\mathbf{a})>27.4$ and $(\mathbf{b})>20$. 


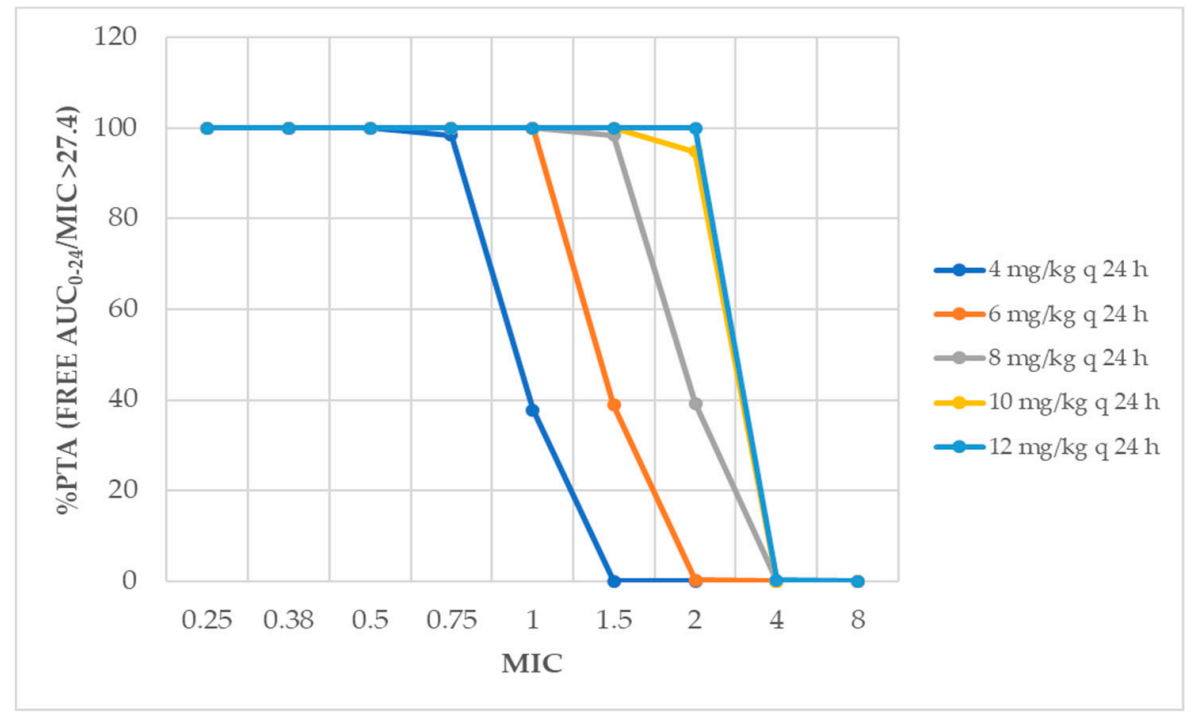

(a)

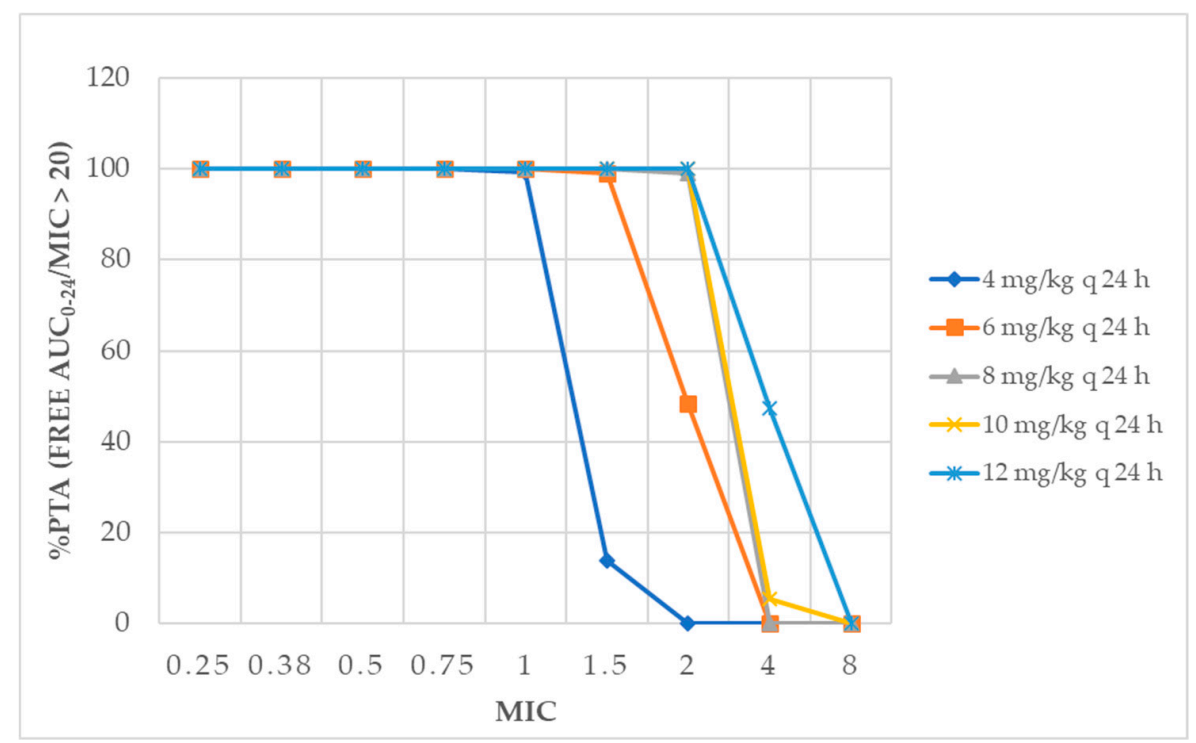

(b)

Figure 3. The percentage of PTA for the different daptomycin dosings for critically ill patients at steady state with targets of $f \mathrm{AUC}_{0-24} / \mathrm{MIC}(\mathbf{a})>27.4$ and $(\mathbf{b})>20$.

Table 1. Cumulative fraction of response of daptomycin with various daptomycin regimens (\%) in Phramongkutklao Hospital.

\begin{tabular}{|c|c|c|c|c|c|}
\hline \multirow{3}{*}{ Daptomycin Dosing } & \multicolumn{4}{|c|}{$\%$ CFR of AUC/MIC } & \multirow{3}{*}{$\begin{array}{l}\text { \% Probability of } \\
\text { Cmin }<24.3 \mathrm{mg} / \mathrm{L}\end{array}$} \\
\hline & \multicolumn{2}{|c|}{$>27.4$} & \multicolumn{2}{|c|}{$>20$} & \\
\hline & First $24 \mathrm{~h}$ & Steady State & First $24 \mathrm{~h}$ & Steady State & \\
\hline $4 \mathrm{mg} / \mathrm{kg} \mathrm{q} 24 \mathrm{~h}$ & 41.47 & 57.24 & 72.86 & 79.42 & 100 \\
\hline $6 \mathrm{mg} / \mathrm{kg} \mathrm{q} 24 \mathrm{~h}$ & 76.74 & 84.37 & 93.22 & 96.68 & 100 \\
\hline $8 \mathrm{mg} / \mathrm{kg} \mathrm{q} 24 \mathrm{~h}$ & 91.98 & 96.35 & 97.61 & 97.9 & 100 \\
\hline $10 \mathrm{mg} / \mathrm{kg} \mathrm{q} 24 \mathrm{~h}$ & 96.99 & 97.81 & 97.91 & 98.03 & 100 \\
\hline $12 \mathrm{mg} / \mathrm{kg} \mathrm{q} 24 \mathrm{~h}$ & 97.87 & 97.92 & 98.0 & 99.0 & 99.99 \\
\hline
\end{tabular}


For VRE, the cumulative fraction of response (CFR) of $\mathrm{fAUC}_{0-24} / \mathrm{MIC}>27.4$ and 20 exceed $90 \%$ with $8-12 \mathrm{mg} / \mathrm{kg}$ daptomycin dosing during the first $24 \mathrm{~h}$ and at steady state, whereas a $6 \mathrm{mg} / \mathrm{kg}$ dosing had a CFR of AAUC $_{0-24} / \mathrm{MIC}>20$ exceeding 90\% (Table 1 ).

\section{Discussion}

This is the first study in Thailand that has tested the in vitro susceptibility of daptomycin against VRE. Even though VRE are not the major multidrug-resistant pathogens in Thailand, their incidence is increasing and bacteremia is most common, especially in the ICU or immunocompromised patients $[1,21]$.

The activity of daptomycin against enterococci was not affected by vancomycin resistance. Previous studies have shown that the daptomycin MIC of E. faecium isolates is higher than that of Enterococcus faecalis $[22,23]$. However, all of the VRE isolates here were E. faecium, and no daptomycin-resistant VRE were observed, and daptomycin showed better activity against VRE strains compared with data from a systematic review. The $\mathrm{MIC}_{90}$ of daptomycin was lower than that reported from other studies (1.5 vs. $2-4 \mu \mathrm{g} / \mathrm{mL}$ ). In the case of daptomycin, MICs of 2 and $4 \mu \mathrm{g} / \mathrm{mL}$ were isolated from urine and blood, respectively, with no history of daptomycin treatment. None had used daptomycin before VRE isolates, but they documented prior use of vancomycin. A correlation between reduced susceptibility to daptomycin and vancomycin was found in S. aureus, but such a correlation was not found in this study [24]. Reduced susceptibility to daptomycin did not correlate with the degree of vancomycin resistance in E. faecium. Daptomycin has bactericidal activity and a good safety profile, whereas linezolid is a bacteriostatic antibiotic associated with myelosuppression after two weeks of treatment. In Thailand, linezolid showed a high MIC against VRE species of E. faecium (MIC 50 $1.5 \mu \mathrm{g} / \mathrm{mL}$ and $\mathrm{MIC}_{90} 2 \mu \mathrm{g} / \mathrm{mL}$ ) [1,21], and it is difficult to achieve the target PK/PD of linezolid with standard dosing [25]. Hence, daptomycin is a potential treatment for VRE infection.

Before 2019, the daptomycin susceptibility breakpoint for enterococci at $4 \mu \mathrm{g} / \mathrm{mL}$ was higher than that of the Staphylococcus and Streptococcus breakpoint $(1 \mu \mathrm{g} / \mathrm{mL})$. This breakpoint was based on a standard dosing of $6 \mathrm{mg} / \mathrm{kg}$ every $24 \mathrm{~h} \mathrm{[26].} \mathrm{A} \mathrm{Monte} \mathrm{Carlo} \mathrm{simulation} \mathrm{study} \mathrm{of} \mathrm{the} \mathrm{standard}$ dose showed that MICs of $2-4 \mu \mathrm{g} / \mathrm{mL}$ could not achieve a PTA exceeding $90 \%$ of survival and the microbiological target of E. faecium [14,16], and daptomycin MICs of 3-4 $\mu \mathrm{g} / \mathrm{mL}$ against E. faecium were associated with microbiological failure [27]. In 2019, the breakpoint of E. faecium was re-evaluated twice. The first revision changed the daptomycin-susceptible breakpoint to $1 \mu \mathrm{g} / \mathrm{mL}$ and the SDD was $2-4 \mu \mathrm{g} / \mathrm{mL}$, with suggested dosings of 6 and $8-12 \mathrm{mg} / \mathrm{kg}$, respectively. The second time, there was no susceptible category and the SDD category was a $8-12 \mathrm{mg} / \mathrm{kg} /$ day daptomycin dosing. The updated breakpoint revision achieved a target $f \mathrm{AUC}_{0-24} / \mathrm{MIC}$ of 12.9 for a $1-\log _{10} \mathrm{CFU}$ reduction in E. faecium in a murine model but not for the target in clinical outcomes [28].

The pharmacokinetics of daptomycin in critically ill patients changed from those of noncritically ill patients, with an increase in daptomycin clearance $(0.4-0.6$ to $0.9-1.05 \mathrm{~L} / \mathrm{h})$ and a slight increase in the volume of distribution (0.08-0.106 to $0.18 \mathrm{~L} / \mathrm{kg}$ ) [29-31]. Augmented daptomycin clearance leads to a lower daptomycin concentration and contributes to higher in-hospital mortality. In our study, the Monte Carlo simulation in critically ill patients at steady state produced results similar to previous data. A daptomycin dosing of 10-12 mg/kg/day can achieve $90 \%$ PTA of survival and microbiological outcomes at MIC $\leq 2 \mu \mathrm{g} / \mathrm{mL}$, and a dosing of $8 \mathrm{mg} / \mathrm{kg} /$ day can achieve $90 \%$ PTA of microbiological target not for survival target at MIC $\leq 2 \mu \mathrm{g} / \mathrm{mL}$ [14]. At the first day, the \%PTA of $f \mathrm{AUC}_{0-24} / \mathrm{MIC}$ was lower than the steady state. At MIC $\leq 2 \mu \mathrm{g} / \mathrm{mL}$, administration of $12 \mathrm{mg} / \mathrm{kg} /$ day achieved $90 \%$ PTA of survival and microbiological target, whereas $10 \mathrm{mg} / \mathrm{kg} /$ day achieved only the microbiological target. No daptomycin dosing achieved $90 \%$ PTA of target at $4 \mu \mathrm{g} / \mathrm{mL}$.

Several clinical studies have shown survival and microbiological eradication in patients with VRE bacteremia to be associated with the dose of daptomycin; by contrast, some studies have not found any benefit. The definition of a high dose varies [14]. Britt et al. showed that high daptomycin dosing $(\geq 10 \mathrm{mg} / \mathrm{kg} /$ day) has lower 30 days mortality compared with medium and standard dosing ( 8 and 
$6 \mathrm{mg} / \mathrm{kg} /$ day, respectively), and both high and medium doses have good microbiological clearance compared with a low dose [12]. According to Chuang et al., higher daptomycin dosing ( $\geq 9 \mathrm{mg} / \mathrm{kg} / \mathrm{day})$ was correlated with lower 14 days mortality compared with low dosing $(<7 \mathrm{mg} / \mathrm{kg} /$ day $)$, regardless of the daptomycin MIC, but they did not find a difference in microbiological outcome [11]. In critically ill patients, we suggest a daptomycin dose of $8 \mathrm{mg} / \mathrm{kg} /$ day with a MIC of $\leq 1 \mu \mathrm{g} / \mathrm{mL}$. Even though a $6 \mathrm{mg} / \mathrm{kg} /$ day dosing can achieve $90 \%$ PTA of MIC $\leq 1 \mu \mathrm{g} / \mathrm{mL}$, concerns about treatment failure and higher mortality with a $6 \mathrm{mg} / \mathrm{kg} /$ day dosing should be considered. Mutations to the liaFSR system have been found [32]. At a MIC of about $2 \mu \mathrm{g} / \mathrm{mL}$, we suggest a loading dose of $12 \mathrm{mg} / \mathrm{kg}$ followed by $10-12 \mathrm{mg} / \mathrm{kg} /$ day. At a MIC of $4 \mu \mathrm{g} / \mathrm{mL}, 12 \mathrm{mg} / \mathrm{kg}$ loading and maintenance doses with ampicillin or ceftaroline should be considered [33]. In our institution, the MIC value is low, and loading and maintenance doses of $8 \mathrm{mg} / \mathrm{kg} /$ day are optimal.

There is an increased risk of skeletal muscle toxicity (myopathy and elevation of CPK) for daptomycin associated with daptomycin dosing and $\mathrm{Cmin}>24.3 \mu \mathrm{g} / \mathrm{L}[10,17]$. In the current study, the risk of musculoskeletal toxicity was low in this population, and a daptomycin dosing of up to $12 \mathrm{mg} / \mathrm{kg} /$ day was found to be safe. Multiple observational studies have shown that a $\geq 8 \mathrm{mg} / \mathrm{kg} / \mathrm{day}$ dosing of daptomycin is not associated with CPK elevation and no serious adverse events were observed $[11,12,14]$. However, the risk of CPK elevation not associated with daptomycin dosing has been reported $[11,30,34]$. Thus, the CPK level should be closely monitored and use with statin is a concern.

There are several limitations of this study. First, several PK/PD targets of E. faecium were reported and the optimal target is unclear [14]. Daptomycin $f \mathrm{AUC}_{0-24} / \mathrm{MIC}>27.4$ is associated with improved survival in low-severity patients and not deep-seated infections [16]. Second, only 48 VRE were isolated for susceptibility testing. Further studies are needed to simulate daptomycin dosing for VRE infection in renal impairment patients.

\section{Materials and Methods}

\subsection{Microbiological Analysis}

VRE strains were collected from each patient who was admitted to the Phramongkutklao Hospital, Bangkok, Thailand from October 2014 to February 2018 and met CDC/NHSN surveillance definitions for specific types of infections or sterile site specimens.

The procedures for in vitro activity were recommended by the CLSI. The vancomycin MIC was determined by broth microdilution (standard powder donated by Siam Pharmaceutical Co., Ltd.). The MIC of daptomycin was determined by E-test strips (Liofilchem, Teramo, Italy) with a range of $0.016-256 \mu \mathrm{g} / \mathrm{mL}$. Incubations at $37^{\circ} \mathrm{C}$ in ambient air were carried out for 18 and $24 \mathrm{~h}$ for daptomycin and vancomycin, respectively. Nonduplicate susceptibility testing of VRE was performed. The percentage of susceptible category was determined using the approved CLSI M100 30th edition breakpoint.

\subsection{Pharmacokinetic and Pharmacodynamic Analysis and Dosing Simulations}

Pharmacokinetic parameters were obtained from a previous study of critically ill patients [29]. Concentration versus time during the first $24 \mathrm{~h}$ and at steady state was determined using a one-compartment model. For pharmacokinetic and pharmacodynamic analysis, a 10,000-subject Monte Carlo simulation (Oracle Crystal Ball) was used to calculate the $f \mathrm{AUC}_{0-24} / \mathrm{MIC}>27.4$ and $f \mathrm{AUC}_{0-24} / \mathrm{MIC}>20$ for survival and microbiological response, respectively, and Cmin $<24.3 \mathrm{mg} / \mathrm{L}$ for safety. The simulation was conducted for various daptomycin dosing regimens $(4,6,8,10$, and $12 \mathrm{mg} / \mathrm{kg} / \mathrm{day}$ ) and actual body weight values (55-65 kg).

The PTA was estimated at MICs of $0.25,0.38,0.5,0.75,1,1.5,2,4$, and $8 \mu \mathrm{g} / \mathrm{mL}$ and the CFR was calculated by \%PTA against MIC distributions of VRE. 


\subsection{Ethical Approval}

The Ethics Review Committee of the Royal Thai Army Medical Department, Bangkok, Thailand approved the study protocol (approval no. Q014b/62).

\section{Conclusions}

Based on the SDD breakpoint for enterococci and conditions with critically ill patients, daptomycin requires a dosing regimen of up to $8 \mathrm{mg} / \mathrm{kg} /$ day. Daptomycin resistance among VRE isolates was not observed in our study, and we found a low prevalence of VRE isolates with an SDD breakpoint. However, longitudinal or multicenter studies are needed to determine the real situation regarding VRE.

Author Contributions: Conceptualization, W.S. and J.H.; methodology, W.S. and J.H.; software, W.S.; validation, W.S. and J.H.; formal analysis, W.S. and J.H.; investigation, W.S. and J.H.; resources, W.S., J.H., and S.T.; data curation, W.S. and J.H.; writing-original draft preparation, W.S. and J.H.; writing-review and editing, W.S., J.H., and D.C.; visualization, W.S. and J.H.; supervision, W.S. and J.H.; project administration, W.S.

Funding: This research received no external funding.

Conflicts of Interest: The authors report no conflicts of interest.

\section{References}

1. Hemapanpairoa, J.; Changpradub, D.; Thunyaharn, S.; Santimaleeworagun, W. Vancomycin-resistant enterococcal infection in a Thai university hospital: Clinical characteristics, treatment outcomes, and synergistic effect. Infect. Drug Resist. 2019, 12, 2049-2057. [CrossRef] [PubMed]

2. Chiang, H.Y.; Perencevich, E.N.; Nair, R.; Nelson, R.E.; Samore, M.; Khader, K.; Chorazy, M.L.; Herwaldt, L.A.; Blevins, A.; Ward, M.A.; et al. Incidence and Outcomes Associated with Infections Caused by Vancomycin-Resistant Enterococci in the United States: Systematic Literature Review and Meta-Analysis. Infect. Control Hosp. Epidemiol. 2017, 38, 203-215. [CrossRef] [PubMed]

3. National Antimicrobial Resistance Surveillance Center. Thailand. Available online: http://narst.dmsc.moph. go.th/ (accessed on 9 September 2019).

4. Baddour Larry, M.; Wilson Walter, R.; Bayer Arnold, S.; Fowler Vance, G.; Tleyjeh Imad, M.; Rybak Michael, J.; Barsic, B.; Lockhart Peter, B.; Gewitz Michael, H.; Levison Matthew, E.; et al. Infective Endocarditis in Adults: Diagnosis, Antimicrobial Therapy, and Management of Complications. Circulation 2015, 132, 1435-1486. [CrossRef] [PubMed]

5. Mermel, L.A.; Allon, M.; Bouza, E.; Craven, D.E.; Flynn, P.; O'Grady, N.P.; Raad, I.I.; Rijnders, B.J.A.; Sherertz, R.J.; Warren, D.K. Clinical Practice Guidelines for the Diagnosis and Management of Intravascular Catheter-Related Infection: 2009 Update by the Infectious Diseases Society of America. Clin. Infect. Dis. 2009, 49, 1-45. [CrossRef] [PubMed]

6. Stevens, D.L.; Bisno, A.L.; Chambers, H.F.; Dellinger, E.P.; Goldstein, E.J.C.; Gorbach, S.L.; Hirschmann, J.V.; Kaplan, S.L.; Montoya, J.G.; Wade, J.C. Practice Guidelines for the Diagnosis and Management of Skin and Soft Tissue Infections: 2014 Update by the Infectious Diseases Society of America. Clin. Infect. Dis. 2014, 59, e10-e52. [CrossRef]

7. Berbari, E.F.; Kanj, S.S.; Kowalski, T.J.; Darouiche, R.O.; Widmer, A.F.; Schmitt, S.K.; Hendershot, E.F.; Holtom, P.D.; Huddleston, P.M., III; Petermann, G.W.; et al. 2015 Infectious Diseases Society of America (IDSA) Clinical Practice Guidelines for the Diagnosis and Treatment of Native Vertebral Osteomyelitis in Adultsa. Clin. Infect. Dis. 2015, 61, e26-e46. [CrossRef]

8. Waller, D.G.; Sampson, A.P. 51-Chemotherapy of infections. In Medical Pharmacology and Therapeutics, 5th ed.; Waller, D.G., Sampson, A.P., Eds.; Elsevier: Amsterdam, The Netherlands, 2018; pp. 581-629. [CrossRef]

9. American Thoracic Society and Infectious Diseases Society of America. Guidelines for the Management of Adults with Hospital-acquired, Ventilator-associated, and Healthcare-associated Pneumonia. Am. J. Respir. Crit. Care Med. 2005, 171, 388-416. [CrossRef]

10. Foolad, F.; Taylor, B.D.; Shelburne, S.A.; Arias, C.A.; Aitken, S.L. Association of daptomycin dosing regimen and mortality in patients with VRE bacteraemia: A review. J. Antimicrob. Chemother. 2018, 73, 2277-2283. [CrossRef] 
11. Chuang, Y.C.; Lin, H.Y.; Chen, P.Y.; Lin, C.Y.; Wang, J.T.; Chen, Y.C.; Chang, S.C. Effect of Daptomycin Dose on the Outcome of Vancomycin-Resistant, Daptomycin-Susceptible Enterococcus faecium Bacteremia. Clin. Infect. Dis. Off. Publ. Infect. Dis. Soc. Am. 2017, 64, 1026-1034. [CrossRef]

12. Britt, N.S.; Potter, E.M.; Patel, N.; Steed, M.E. Comparative Effectiveness and Safety of Standard-, Medium-, and High-Dose Daptomycin Strategies for the Treatment of Vancomycin-Resistant Enterococcal Bacteremia among Veterans Affairs Patients. Clin. Infect. Dis. Off. Publ. Infect. Dis. Soc. Am. 2017, 64, 605-613. [CrossRef]

13. Humphries, R.M. The New, New Daptomycin Breakpoint for Enterococcus spp. J. Clin. Microbiol. 2019, 57, e00600-e00619. [CrossRef] [PubMed]

14. Satlin, M.J.; Nicolau, D.P.; Humphries, R.M.; Kuti, J.L.; Campeau, S.A.; Lewis, J.S., II; Weinstein, M.P.; Jorgensen, J.H.; Clinical and Laboratory Standards Institute Subcommittee on Antimicrobial Susceptibility Testing and Ad Hoc Working Group on Revision of Daptomycin Enterococcal Breakpoints. Development of Daptomycin Susceptibility Breakpoints for Enterococcus faecium and Revision of the Breakpoints for other Enterococcal species by the Clinical and Laboratory Standards Institute. Clin. Infect. Dis. 2019. [CrossRef] [PubMed]

15. Safdar, N.; Andes, D.; Craig, W.A. In vivo pharmacodynamic activity of daptomycin. Antimicrob. Agents Chemother. 2004, 48, 63-68. [CrossRef] [PubMed]

16. Avery, L.M.; Kuti, J.L.; Weisser, M.; Egli, A.; Rybak, M.J.; Zasowski, E.J.; Arias, C.A.; Contreras, G.A.; Chong, P.P.; Aitken, S.L.; et al. Pharmacodynamic Analysis of Daptomycin-treated Enterococcal Bacteremia: It Is Time to Change the Breakpoint. Clin. Infect. Dis. Off. Publ. Infect. Dis. Soc. Am. 2019, 68, 1650-1657. [CrossRef] [PubMed]

17. Bhavnani, S.M.; Rubino, C.M.; Ambrose, P.G.; Drusano, G.L. Daptomycin exposure and the probability of elevations in the creatine phosphokinase level: Data from a randomized trial of patients with bacteremia and endocarditis. Clin. Infect. Dis. Off. Publ. Infect. Dis. Soc. Am. 2010, 50, 1568-1574. [CrossRef] [PubMed]

18. Boucher, B.; Wood, G.; Swanson, J. Pharmacokinetic Changes in Critical Illness. Crit. Care Clin. 2006, 22, 255-271. [CrossRef]

19. Pea, F. Plasma pharmacokinetics of antimicrobial agents in critically ill patients. Curr. Clin. Pharmacol. 2013, 8, 5-12.

20. Roberts, J.A.; Abdul-Aziz, M.H.; Lipman, J.; Mouton, J.W.; Vinks, A.A.; Felton, T.W.; Hope, W.W.; Farkas, A.; Neely, M.N.; Schentag, J.J.; et al. Individualised antibiotic dosing for patients who are critically ill: Challenges and potential solutions. Lancet Infect. Dis. 2014, 14, 498-509. [CrossRef]

21. O'Driscoll, T.; Crank, C.W. Vancomycin-resistant enterococcal infections: Epidemiology, clinical manifestations, and optimal management. Infect. Drug Resist. 2015, 8, 217-230. [CrossRef]

22. Streit, J.M.; Jones, R.N.; Sader, H.S. Daptomycin activity and spectrum: A worldwide sample of 6737 clinical Gram-positive organisms. J. Antimicrob. Chemother. 2004, 53, 669-674. [CrossRef]

23. Cantón, R.; Ruiz-Garbajosa, P.; Chaves, R.L.; Johnson, A.P. A potential role for daptomycin in enterococcal infections: What is the evidence? J. Antimicrob. Chemother. 2010, 65, 1126-1136. [CrossRef] [PubMed]

24. Patel, J.B.; Jevitt, L.A.; Hageman, J.; McDonald, L.C.; Tenover, F.C. An association between reduced susceptibility to daptomycin and reduced susceptibility to vancomycin in Staphylococcus aureus. Clin. Infect. Dis. Off. Publ. Infect. Dis. Soc. Am. 2006, 42, 1652-1653. [CrossRef] [PubMed]

25. Yang, M.; Zhang, J.; Chen, Y.; Liang, X.; Guo, Y.; Yu, J.; Zhu, D.; Zhang, Y. Optimization of linezolid treatment regimens for Gram-positive bacterial infections based on pharmacokinetic/pharmacodynamic analysis. Future Microbiol. 2017, 12, 39-50. [CrossRef] [PubMed]

26. Humphries, R.M.; Pollett, S.; Sakoulas, G. A current perspective on daptomycin for the clinical microbiologist. Clin. Microbiol. Rev. 2013, 26, 759-780. [CrossRef] [PubMed]

27. Shukla, B.S.; Shelburne, S.; Reyes, K.; Kamboj, M.; Lewis, J.D.; Rincon, S.L.; Reyes, J.; Carvajal, L.P.; Panesso, D.; Sifri, C.D.; et al. Influence of Minimum Inhibitory Concentration in Clinical Outcomes of Enterococcus faecium Bacteremia Treated with Daptomycin: Is it Time to Change the Breakpoint? Clin. Infect. Dis. Off. Publ. Infect. Dis. Soc. Am. 2016, 62, 1514-1520. [CrossRef] [PubMed]

28. Kidd, J.M.; Abdelraouf, K.; Asempa, T.E.; Humphries, R.M.; Nicolau, D.P. Pharmacodynamics of Daptomycin against Enterococcus faecium and Enterococcus faecalis in the murine thigh infection model. Antimicrob. Agents Chemother. 2018, 62, e00506-e00518. [CrossRef] [PubMed] 
29. Falcone, M.; Russo, A.; Venditti, M.; Novelli, A.; Pai, M.P. Considerations for higher doses of daptomycin in critically ill patients with methicillin-resistant Staphylococcus aureus bacteremia. Clin. Infect. Dis. Off. Publ. Infect. Dis. Soc. Am. 2013, 57, 1568-1576. [CrossRef]

30. Bubalo, J.S.; Munar, M.Y.; Cherala, G.; Hayes-Lattin, B.; Maziarz, R. Daptomycin pharmacokinetics in adult oncology patients with neutropenic fever. Antimicrob. Agents Chemother. 2009, 53, 428-434. [CrossRef]

31. Soraluce, A.; Asin-Prieto, E.; Rodriguez-Gascon, A.; Barrasa, H.; Maynar, J.; Carcelero, E.; Soy, D.; Isla, A. Population pharmacokinetics of daptomycin in critically ill patients. Int. J. Antimicrob. Agents 2018, 52, 158-165. [CrossRef]

32. Kebriaei, R.; Rice, S.A.; Singh, K.V.; Stamper, K.C.; Dinh, A.Q.; Rios, R.; Diaz, L.; Murray, B.E.; Munita, J.M.; Tran, T.T.; et al. Influence of Inoculum Effect on the Efficacy of Daptomycin Monotherapy and in Combination with beta-Lactams against Daptomycin-Susceptible Enterococcus faecium Harboring LiaSR Substitutions. Antimicrob. Agents Chemother. 2018, 62. [CrossRef]

33. Smith, J.R.; Barber, K.E.; Raut, A.; Aboutaleb, M.; Sakoulas, G.; Rybak, M.J. beta-Lactam combinations with daptomycin provide synergy against vancomycin-resistant Enterococcus faecalis and Enterococcus faecium. J. Antimicrob. Chemother. 2015, 70, 1738-1743. [CrossRef] [PubMed]

34. Metwali, H.; Elder, K. Dose-independent daptomycin associated rhabdomyolysis: Case report. J. Basic Clin. Pharm. 2018, 9, 286-288.

(C) 2019 by the authors. Licensee MDPI, Basel, Switzerland. This article is an open access article distributed under the terms and conditions of the Creative Commons Attribution (CC BY) license (http://creativecommons.org/licenses/by/4.0/). 